\title{
The Effects of Ostentatious Calls in Gsm Networks
}

\author{
Osahenvemwen O.A., \\ Department Of Electrical And \\ Electronics \\ Faculty Of Engineering And \\ Technology. \\ Ambrose Alli, University. \\ Ekpoma, Edo State, Nigeria.
}

\author{
Edeko F.O. \\ Department Of Electrical And \\ Electronics \\ Faculty Of Engineering And \\ Technology. \\ University Of Benin. \\ Benin, Edo State, Nigeria
}

\author{
Emagbetere J. \\ Department of Elect/Elect \\ Engineering \\ Faculty of Engineering and \\ Technology. \\ University of Benin \\ Benin City, Edo State.
}

\begin{abstract}
In this paper, we investigate the possible effect of ostentatious (flash) calls in mobile communication networks (GSM) in Nigeria. The GSM network consists of physical and logical channels used to convey digit information signal from one network element to another. The Globacom network in Nigeria was investigated in a period of one year duration. An average traffic data (A-interface MSC) were collected from the OMC-network element. Also, it was observed from the result analysis that complete calls which is a major factor in revenue generation consist of both answer calls with 42 percentage and unanswered calls with 58 percentages. These unanswered calls are made up of both redial calls and ostentatious (flash) calls which are transmitted through the limited transmission channels without financial benefit accrue to the mobile communication operators. It were deduced from investigation that the traffic in erlang for average number of unanswered calls in 1 hour is 4151.92 erlang and one (1) call is 0.0023 erlang. In this paper, we highlighted the possible effects of unanswered calls, solutions of reducing the high number of unanswered calls and reduction in unanswered calls will leads to remarkable low number of block calls experience in the Mobile Communication network (GSM).
\end{abstract}

\section{Keywords}

Ostentatious (flash) calls, Redial calls, unanswered calls, channels and revenue.

\section{INTRODUTION}

As the demand for wide variety of service such as emails, stock quotes, surf the internet and electronic commerce over the air or M-commerce are needed from mobile operators. In order, to achieve a good desired Quality of Service (QOS) the issue of transmission channels must be handle with great important. The transmission channels are limited in resources and it's expensive. This transmission channels are used to convey digit information signal in bit from one network element to another [8],[9]. The $13 \mathrm{kbps}$ bit rate is transfer from the Mobile Station (MS) through (traffic full rate channels in) the air-interface to the Mobile Switching Centre (MSC) through the A-interface at $64 \mathrm{kbps}$. The Transcoder (TC) is responsible for the conversion from $16 \mathrm{kbps}$ to $64 \mathrm{kbps}$ and vice versa. The $16 \mathrm{kbps}$ bit rate resulted from $13 \mathrm{kbps}$ full rate traffic channels, with additional $3 \mathrm{kbps}$ used between the transcoder and the BTS for carrying the 260-bit vocoder block (equivalent with $20 \mathrm{~ms}$ of speech) and for inband signaling (information about the speech coding algorithm, type of call etc)[7] shown in Fig 1.

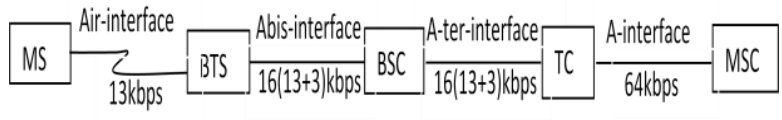

Fig. 1: The GSM interface system

The air-interface or um-interface uses two types of channels; these are the physical channel (timeslot) and logical channels [6]. The physical channels are generate from a set of bandwidth (example GSM 900) partition into 124 carrier frequencies, each carrier frequency is subdivided into 8 timeslots or physical channels uses Time Division Multiple Access (TDMA) techniques. These timeslots are used to convey logical channels such as traffic channels (full rate traffic channel $13 \mathrm{kbps}$ and half rate traffic channel 5.6kbps) and Control Channels (CCHs) which is divided into three channels such are Broadcast Control Channels (BCCHs), Common Control Channels (CCCHs) and Dedicated Control Channels (DCCH) [2],[1]. The MS make used of BCCHs during initialization, it consist of three channels. Thereafter, the MS is ready to make or received calls using four (4) other different logical channels with a signaling rate of $64 \mathrm{kbps}$ shown Fig 2. Abis-interface is the interface between BTS and the BSC .It uses a PCM 30 interface with a transmission rate of $2.048 \mathrm{Mbps}$, which is partitioned into 32 channels of 64kbps each [4],[3]. 


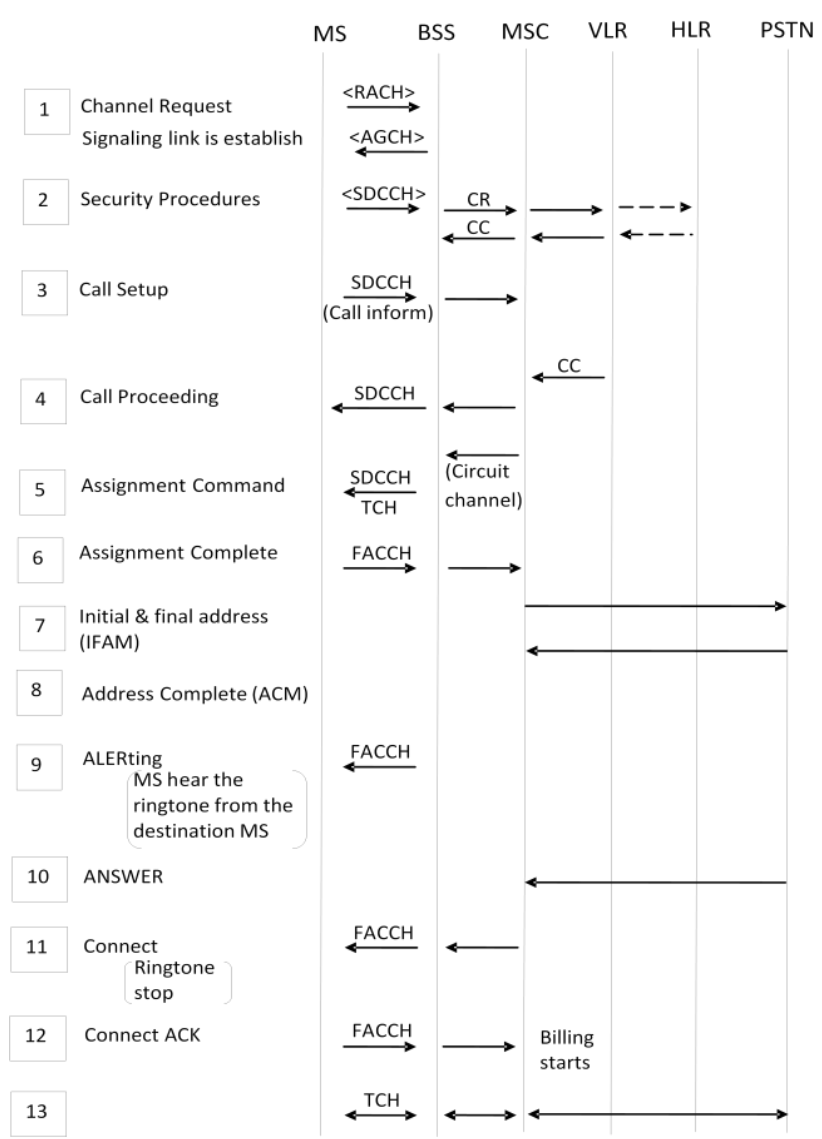

Source: (Introduction to GSM, training manual Motorola Ltd)

Fig. 2: MS call sequence in GSM

Voice calls (digital signal) are convey from MSs to MSC through different traffic interfaces. These traffic interfaces (between air-interface to A-interface) often experience traffic in the system which is measure in Erlang. The traffic flow in the mobile communication network can be characterized into three traffic categories, show in Fig 3.

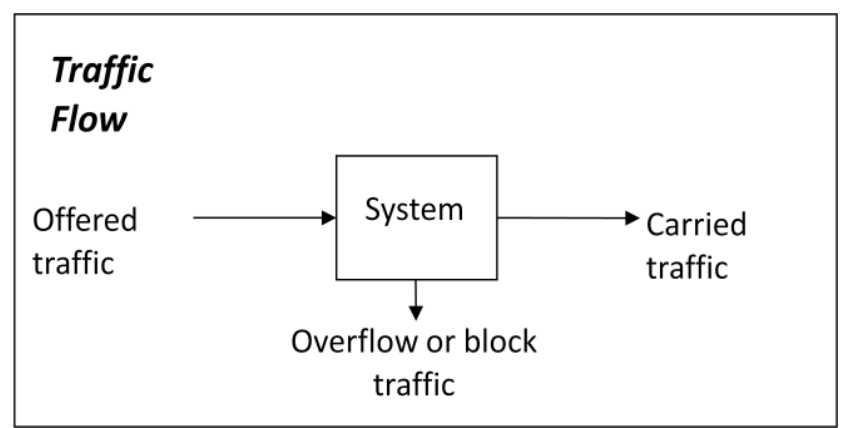

Source: (www.wseas.us/e-library/transactions/ communication/2008[10])

\section{Fig. 3: Traffic flow chart}

Traffic analysis involves the use of offered traffic, carried traffic and block traffic which is measured in Erlang [5]. This traffic in erlang estimation involves the use of total number of call intensity and average holding time [3]. The carried traffic in erlang is estimated with the number of complete calls or successful calls within a period of time. The number of carried traffic or complete calls is used to evaluate the performance of the mobile communication network. In addition, it's used to estimate the revenue generation in the network. The complete calls comprises of answer calls and unanswered calls. The answer calls is the benchmark for revenue generation for mobile network operators, while unanswered calls occupies or uses the limited and expensive traffic channels without generating revenue for the mobile communication network operators. These unanswered calls consist of redial calls and ostentatious calls. Ostentatious calls is also referred to as flash calls which mean display of call intended to impress the calling part.

\section{METHODOLY}

In the GSM network (mobile communication network) traffic data were collected from Operation and Maintenance centre (OMC) which is implemented as Operation and Support System (OSS). The GSM network under investigation is Globacom limited in Nigeria, for a period of one year. The traffic data collected contains the following information as follows, the route ID, average complete calls, average attempts calls, average answer calls, time, data, time interval period.

Table 1: Average calls intensity in the A- interface route

Source :(Globacom Network Switching Department)

\begin{tabular}{|c|c|c|c|c|c|c|}
\hline $\mathrm{N}$ & 怤 蒙 & 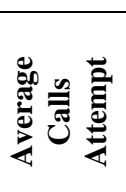 & 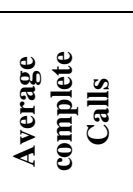 & 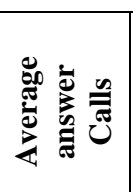 & 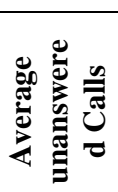 & $\begin{array}{l}\stackrel{n}{\bar{J}} \\
\frac{n}{\ddot{0}} \\
\frac{0}{\infty}\end{array}$ \\
\hline 1 & BSC 10_1 & 596877 & 446450 & 196676 & 249774 & 150427 \\
\hline 2 & BSC 10_2 & 708950 & 560907 & 264402 & 296505 & 148043 \\
\hline 3 & BSC (12) & 1366646 & 1039033 & 482134 & 556899 & 327613 \\
\hline 4 & BEN13_1(15) & 52901 & 41185 & 16359 & 24826 & 11716 \\
\hline 5 & MSC 11-(0) & 567808 & 552984 & 95741 & 457243 & 14824 \\
\hline 6 & MSC 16(1) & 203973 & 168775 & 75273 & 93502 & 35198 \\
\hline 7 & MSC 17(11) & 898549 & 702891 & 331572 & 371319 & 195658 \\
\hline 8 & MSC35(6) & 3171 & 3023 & 1561 & 1462 & 148 \\
\hline 9 & $\mathrm{MSC} 20$ & 108275 & 91501 & 41138 & 50363 & 16774 \\
\hline 1 & MSC 53(8) & 420299 & 365106 & 169258 & 195848 & 55193 \\
\hline
\end{tabular}

Also call setup time was determined for different mobile communication network in Nigeria using the same mobile equipment (Nokia) to reduced error occurrence in the experiment. When, the Mobile Station (MS) as finished initializing, the MS is ready to make or received calls. The call setup time start from the moment the subscribers press the "send" bottom and end with ring tone before the subscriber press the "ok" bottom which trigger the released of Traffic Channel (TCH) used in conversion. 
Table 2 Call setup time for GSM Networks in Nigeria

\begin{tabular}{|c|l|l|l|}
\hline S/N & $\begin{array}{l}\text { Networks } \\
\text { operators }\end{array}$ & $\begin{array}{l}\text { Average Calls } \\
\text { Attempt }\end{array}$ & $\begin{array}{l}\text { CALL SETUP } \\
\text { TIME }\end{array}$ \\
\hline 1 & MTN & MTN & 00.00 .07 .25 \\
\hline 2 & MTN & GLO & 00.00 .10 .03 \\
\hline 3 & MTN & ETISALAT & 00.00 .09 .56 \\
\hline 4 & MTN & AIRTEL & 00.00 .06 .52 \\
\hline 5 & GLO & GLO & 00.00 .08 .28 \\
\hline 6 & GLO & MTN & 00.00 .08 .17 \\
\hline 7 & GLO & ETISALAT & 00.00 .09 .04 \\
\hline 8 & GLO & AIRTEL & 00.00 .08 .20 \\
\hline 9 & AIRTEL & AIRTEL & 00.00 .06 .89 \\
\hline 10 & AIRTEL & MTN & 00.00 .07 .17 \\
\hline 11 & AIRTEL & GLO & 00.00 .08 .86 \\
\hline 12 & AIRTEL & ETISALAT & 00.00 .07 .67 \\
\hline 13 & ETISALAT & ETISALAT & 00.00 .08 .29 \\
\hline 14 & ETISALAT & MTN & 00.00 .07 .52 \\
\hline 15 & ETISALAT & GLO & 00.00 .08 .68 \\
\hline 16 & ETISALAT & AIRTEL & 00.00 .07 .46 \\
\hline & & & \\
\hline
\end{tabular}

\section{RESULT DISCUSSION}

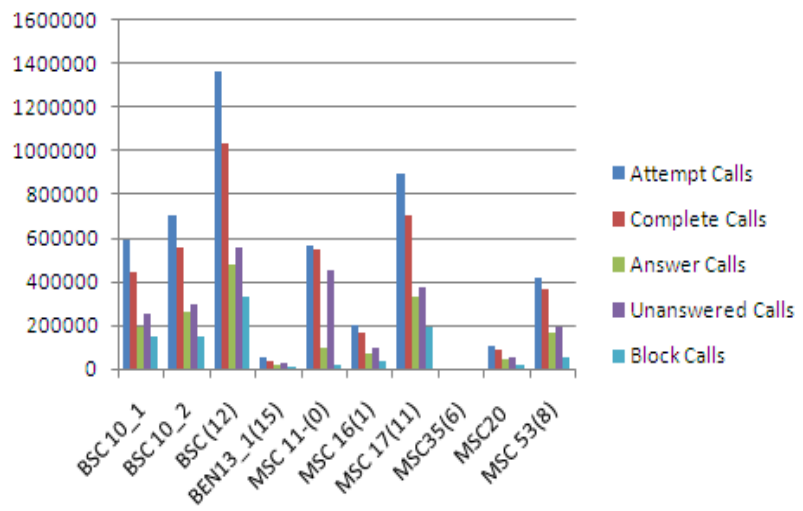

Fig 4: Different group of calls against $10 \mathrm{~A}$-interface routes

In Fig 4, shown calls intensity categories in the mobile communication network (GSM) in different A-interface routes. The calls intensity is categorized into attempt calls, complete calls, answer calls, unanswered calls and blocks calls. From the Fig 4, it is observed that average attempt calls have the highest number of calls; followed by average complete calls, average unanswered calls, average answer call and average number of block calls.

\section{Average Call Intensity}

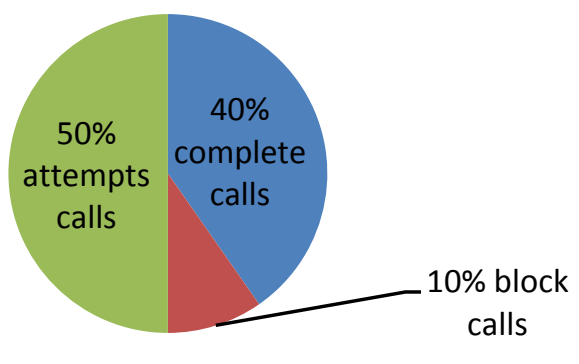

Fig. 5: Show the three major traffic characteristic with their various percentage

In Fig 5 show the pie chart of traffic characteristic with their various percentages from the Table 1.Traffic characteristic are offered traffic (attempts calls),carried traffic (complete calls) and blocks calls, experience due to lack equipment (network capacity). From the pie chart the total number of block calls experience in the system is $10 \%$ which is high compared to Nigeria Communication Commission (NCC) recommended value, give as ratio 2:100 (0.02).

\section{Composition of complete calls}

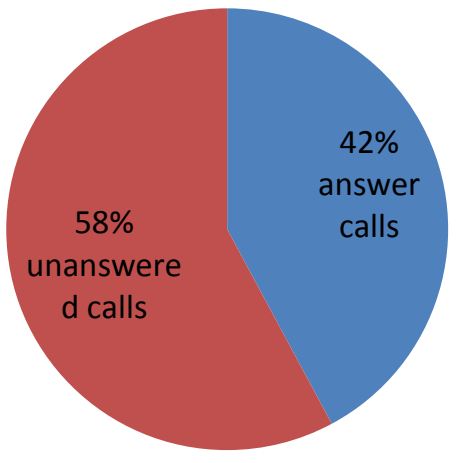

Fig. 6: The composition of complete calls with their respective percentage

In Fig 6 show that complete calls or successful calls consist of answer calls and unanswered calls with their various percentage. This aspect of complete call section is responsible for revenue generation in mobile communication network (GSM). It is observed form the pie chart in Fig 6 that the numbers of unanswered calls in GSM network overweigh the number of answer calls in the system. The different between the complete calls and the answer calls is the unanswered calls. The unanswered calls consist of redial calls and ostentatious (flash) calls which constitute a lager percentage of the complete calls. This high number of unanswered calls does not generate revenue for the mobile network and it's wasteful to the mobile network. 


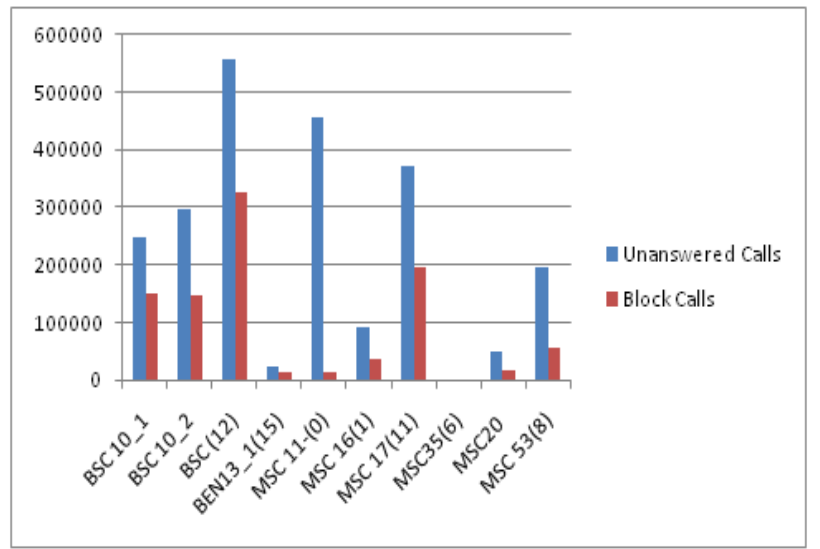

Fig. 7: The variation in the values between unanswered calls and block calls against different routes

In Fig 7 shown the number of unanswered calls and blocks calls in each route in the mobile network. It is observed that the number of unanswered calls is higher than the presence number of block calls in the system. Therefore if the number of unanswered calls can be reduced, than the number of blocks call will also be reduce respectively.

\subsection{The Effects of Ostentatious Calls}

The mobile communication industries are aimed in making profit, therefore the number of complete calls (carried traffic) should be giving great attention, which is the benchmark of revenue generation. Based on the result analysis, complete calls comprises of answer calls and unanswered calls. In Fig 6 the numbers of unanswered calls, $58 \%$ overweigh the number of answer calls $42 \%$ in the mobile network. This high number of unanswered calls which is made-up of ostentatious calls and redials calls in the network is worrisome.

Therefore, the possible effects of unanswered calls in mobile communication network are as follows. The unanswered calls are transmitted through the limited and expensive channels (network capacity) without financial benefit, which leads to losses of financial revenue form the mobile network operators. The high number of unanswered calls in network deprives genuine calls from using the limited channels capacity at a particular point in time, those deprives calls resulting as block calls in the system. The presence of ostentatious calls and unanswered calls causes a major alteration or inflation in traffic data use for analysis. This alteration in traffic data may lead to inaccurate prediction of blocking probability in mobile communication network.

\subsection{The Possible Solution to Ostentatious Calls}

The possible solution to reduced the high number of unanswered calls in mobile network are as follows

- The mobile communication network in Nigeria have tried in team of surviving in this environment of infrastructural decay such are unstable power supply, insecurity, unstable salary structure, Government policy etc. In real sense the mobile network operators in Nigeria are supernatural industry, but the mobile network operators should take a further step, to reduce call rate (tariff or charges) to enable subscribers to pay for calls and not to make ostentatious (flash) calls.
- The used of voice mail technology should be encourage with low tariff (charges).

- The introduction of postpaid technology should be re- introduced for local calls, specified within some amount depending on your initial prepaid capacity.

- The ostentatious calls should attract little charges, to discourage subscribers from making ostentatious call.

\subsection{Evaluation of Ostentatious (Unanswered) Calls}

Traffic is a term used to quantify usage, it is measured in Erlang and the formula is give as

$A=\frac{N X A H T}{3600}$

$\mathrm{N}=$ Number of calls, A= Traffic In Erlang, AHT = Average Holding Time

In Table 1, S/No 1, Route ID BSC10_1 unanswered calls values is 249774 .

The total number of unanswered calls in a day is divided by 24 which is the number of hours in a day, used to obtain the average hourly calls.

$\therefore$ Average hourly calls $=\frac{249774}{24}=10407.25$ calls

The Average Holding Time (AHT) formula is giving as

$A H T=\frac{\text { total time }(\text { secs })}{\text { Time interval }}$

(2)

In Table 2, the setup time for various network operators are carry out .In this analysis will assume that the subscribers are in Globacom network subscriber. Therefore the corresponding value is 08.28 .

Therefore the total time in seconds for a set of 10407 subscribers is as setup time multiple by average hour calls

$\therefore 08.28 \times 10407.25=86172.03$

$A H T=\frac{86172.03}{60}=1436.2005 \mathrm{Secs}$

The total number of unanswered calls in average of one (1) hour is express in traffic Erlang below.

traffic in one hour $=\frac{10407.25 \times 1436.2}{3600}=4151.92$ Erlang

- (3)

The estimated average traffic in erlang within one hour for number of unanswered calls is give as 4151.92erl.

Traffic in erlang for one unanswered call can estimated as follows,

If $\mathrm{N}$ represents the number of call, AHT is estimated from Table 2 call setup time and assume the subscribers are Globacom subscriber. The calls setup time for Globacom is 08.28 secs.

Average traffic in erlang for 1 unanswered call $=\frac{1 \times 08.28}{3600}=0.0023$ erlang -

(4)

In the traffic in erlang values estimated, it was observed that 1 unanswered call, occupies 0.0023 erlang and a set of number of unanswered calls within one hour result to total value of 4151.92 erlang.

\section{CONCLUSION}

In this paper, we investigated the possible effect of ostentatious (flash) calls in mobile communication network. The traffic data were collected from OMC in Globacom limited at A-interface MSC point. The result analysis in Fig 6 shown, that complete calls is benchmark for revenue generation and it consist of both answer calls and unanswered calls. The total numbers of unanswered calls overweigh the 
total numbers of answer calls using the expensive and limited channels in the mobile network. The high number of unanswered calls is worrisome, it comprise of ostentatious (flash) calls and redial calls. The possible effects of unanswered (ostentatious) calls in mobile communication network are follows. Firstly, the unanswered calls are transmitted through the limited and expensive network channels without financial benefit accrue to the mobile network operators. The high number of unanswered calls can deprive genuine calls from using or passing through the limited channels network at a particular point in time. These deprive calls now result as block calls in the network. The presence of high number of ostentatious (unanswered) calls causes a major alteration or inflation in traffic data. This alteration in traffic data used for traffic analysis may leads to inaccurate prediction of blocking probability in mobile communication network.

The possible solution to reduced the high number of unanswered calls are

- The mobile communication tariff (charges) should be reduced to the lowest minimum to enable subscribers to make calls.

- The used of voice mail technology, should be encourage with low tariff.

- The postpaid system should be introduced for local calls, specified within some amount depending on your initial prepaid capacity.

- The ostentatious calls should attract little charges, to discourage subscribers from making ostentatious call.

In addition, it was deduced form result analysis that traffic in erlang estimated for a number of unanswered calls for one hour is 4151.92 erlang and for 1 (one) call is 0.0023 erlang.

\section{REFERENCE}

[1] Alexei B., Placido R.P, Alvaro S.N, Ruddy P.P., Rebecca F.P. (2009)“A Novel model for optimized GSM Network Design", int. journal of computer sci., Vol. 4 NO.1\&2 ,PP 44-48.
[2] Boulmalf M., Abrache J.,Aouam T. and Harroud H,(2009) “Traffic Analysis for GSM Network"IEEE journal, pp 498-502.

[3] CPO2 (2002). Introduction to GSM Cellular, training Manual Motorola Ltd. Pg 172-178, 192-223

[4] Gunner, H. (1998). 'GSM Network' $1^{\text {st }}$ Edition Artech House Boston page 113-129, 246-3Ericsson Radio System AB, (1998), GSM System Survey, Course Documentation EN/LZT/123 3321 RZB p77.

[5] Jahangir H. S.,Seppo J.H and Mika R(2000) "performance Analysis of GSM traffic channel capacity with(out)high speed circuit switched data" ,IEEE Semiannual Vehicular Technology Conference pp16031609.

[6] Madhusmita P. and Saraju P.P (2011) "Traffic Analysis and optimization of GSM Network " IJCSI Int.journal of computer sci. Issues, Special Issue,ICVCI-2010 ,ISSN:1694-0814.

[7] Rappaport S.T. (2003) wireless communication principles and practice, $2^{\text {nd }}$ Edition, prentice Hall of india private limited, new Delhi, Page 35-62.

[8] Regis J. (2002). Broadband Telecommunication Handbook $2^{\text {nd }}$ Edition, McGraw Hill, pg 126-186, 326412 .

[9] Roger, L. (2004). Telecommunication System Engineering $4^{\text {th }}$ Edition, page 7, 9.

[10] Traffic Characterization for Mobile Networks (2002) http://www.supcom.mincom.tn/ mediation/articles/,62302. Pdf page 4-6.

[11] Traffic Flow (2008) http://www.wseas.us/elibrary/transactions/ communication/2008/27-144. Pdf page 1-2. 